\title{
A luva e a mão (uma história de salvação)
}

\section{Rosa Maria Martelo \\ Universidade do Porto}

Resumo: Na obra de Adília Lopes há dois poemas nos quais a experiência do sujeito é figurada enquanto relação entre a luva (que fica à vista) e a mão (que se esconde, mas talvez para poder continuar à vista). Partirei destes dois poemas para analisar as relações entre Adília e outro "eu" presente na obra, de resto, com existência no registo civil: Maria José Fidalgo de Oliveira (aliás Zé, aliás o Cavaleiro de Oliveira, aliás "freira poetisa barroca", etc.). Que contrato de leitura nos é proposto quando, em Manhã e Bandolim, as fotos de Maria José ainda criança surgem acompanhadas de legendas como esta, "Adília, Verão de 1964"? Como entender que o nome "Adília" remeta para a infância de Maria José, que aconteceu muito antes de esse nome de autor ter surgido nos livros agora reunidos em Dobra? Responder a estas questões passa por interrogar várias formas de hibridismo presentes na escrita de Adília Lopes.

Palavras-chave: Adília Lopes, poesia, autobiografia, autoficção, hibridismo

Abstract: In Adília Lopes's work, there are two poems that describe the subject's experience as the relationship between the glove (which is visible) and the hand (which is hidden, but perhaps hoping to be seen). By addressing these two poems, I will analyze the relations between "Adília" and another self (another "I") also present in her writings: Maria José da Silva Fidalgo de Oliveira, aka Zé, aka Cavaleiro de Oliveira, aka "a Baroque nun-poet", etc. What kind of reading protocol are we dealing with, when, in Manhã and Bandolim, the photos of a young Maria José are accompanied by subtitles such as "Adília, Summer 1964"? How can we understand the use of the name "Adília" in the context of Maris José’s childhood, long before Adília Lopes's 
name appeared in the poetry books now collected in Dobra? Answering these questions will lead us to consider different forms of hybridism in Adília Lopes's writing.

Keywords: Adília Lopes, autobiography, autofiction, hybridism

Marta \& Maria acopladas fundam uma firma no firmamento

\section{1.}

O dístico em epígrafe provém do poema "Lúcia no Saldanha em Pulgas", que pertence ao livro Clube da Poetisa Morta, de Adília Lopes (1997). Tanto o dístico quanto o inesperado título do poema aludem ao célebre tema musical Lucy in de Sky with Diamonds, dos Beatles, o qual, por sua vez, se dizia fazer referência ao acrónimo LSD e aos efeitos alucinogénios do ácido lisérgico. ${ }^{1}$ Atendendo a que "Lúcia no Saldanha em Pulgas" inclui diversas referências a Cristo e ao pano da Verónica, descrito como "auto-retrato dos autoretratos alta costura" (2016: 293), Marta e Maria podem ser identificadas como as duas irmãs de Lázaro. E, a ser assim, a articulação discursiva entre "firma" e "firmamento" que Ihes está associada não se estabelece apenas por atracção fonética, mas remete também para a origem bíblica das duas personagens. Por outro lado, os versos "Marta e Maria acopladas fundam/ uma firma no firmamento" também evidenciam um gosto pelas dualidades que é determinante na escrita de Adília Lopes. O poema imediatamente anterior, intitulado "Op-Art", começava deste modo: "A poetisa é Marta/ e é Maria/ mas a máquina de costura/ encravou/ e Jesus hoje não passou" (2014: 290). Ou seja, a poetisa reúne as identidades diferenciadas da diligente Marta e da contemplativa Maria; e, no entanto, momentos há em que nem uma nem outra podem fazer trabalhar a máquina da escrita/costura, pelo que o texto (a visitação da poesia) não acontece.

Na obra de Adília Lopes, esta dualidade - Marta e Maria - é equivalente à dupla que reúne Adília e Maria José, que também graças à máquina de coser fundaram juntas uma 
firma no firmamento - no caso, entre as estrelas da escrita contemporânea. E entenda-se aqui coser como ligar, combinar, unir tessituras, pedaços de discurso, fazer roupas novas com vestidos velhos. Dobrar (Dobra é o título que reúne a obra publicada até 2014) e cerzir textos que misturam o novo e o usado, eis o trabalho de Marta e Maria, aliás Adília Lopes e Maria José da Silva Viana Fidalgo de Oliveira, dois nomes unidos de forma bem mais complexa do que é habitual nos casos de pseudonímia.

Quando pensamos nas formas de criatividade pós-modernistas que Marjorie Perloff circunscreveu na expressão "génio não original", e que viu antecipadas no hibridismo de Das Passagen - Werk, de Benjamin, uma obra feita de "justaposição de citação poética, anedota, aforismo, parábola, prosa documental, ensaio pessoal, fotografia, diagrama" (Perloff 2013: 58), Adília Lopes é, sem dúvida, uma das figuras mais representativas, uma autora em que o processo de citação e colagem produziu assinalável novidade poética e também inegável eficácia ao nível da crítica da sociedade de consumo e do produtivismo neo-liberal. A obra de Adília Lopes assenta numa prodigiosa memória verbal, trabalha uma espécie de arquivo de curiosidades discursivas, das mais eruditas às mais populares e familiares; nesse acervo está inscrito o choque que o capitalismo global e tecnológico exerce sobre o mundo contemporâneo, e muito particularmente sobre o Portugal no qual nasceu e cresceu Maria José da Silva Viana Fidalgo de Oliveira, que tinha quinze anos quando se deu a Revolução dos Cravos.

De resto, em "Poesia e Gestão", de Z/S, Adília apresenta-se ironicamente como "uma empresária de sucesso" e recorda que "[a] marca Adília existe no mercado desde 1984" (2016: 74). Com evidente ironia, acrescenta: "Tenho um nicho de mercado". Para logo esclarecer, com aquela precisão filológica que the caracteriza o estilo: "Nos anos 60-70 estavam na moda os nichos dentro de casa, os nichos nos nichos. Punham-se lá umas loiças de Cantão e uns santos de pau santo. Sou um caso de empreendedorismo" (ibidem).

Basta confrontar a deriva semântica aqui suscitada pela palavra "nicho" com a reflexão desenvolvida no texto "A trapologia", do mesmo livro, para que não restem dúvidas acerca do que move Adília Lopes enquanto "empresária de sucesso":

No princípio dos anos 70 a professora de Trabalhos Oficinais já não falava de trapos, de tapetes de trapos, de tapeçaria, já era uma doutora da mula ruça que só falava de trapologia. Tinha começado o 
palavreado pseudo-científico, pseudo-tecnológico, essa praga da língua, esse embuste que hoje impera, já não se pode falar português, só a trapologia, só essa língua de trapos é que vale. Ainda havemos de ser multados por não usarmos esse lindo jargão, essa baba. (2016: 103)

Ainda voltarei ao processo de dobrar e cerzir próprio da "marca Adília", tão avessa ao novo-riquismo verbal desta "trapologia", e tão dedicada ao exercício de análise e desmascaramento ironista dos usos verbais da sociedade contemporânea. Mas por agora destacaria esta dualidade, reconhecidamente estruturante na obra: Marta \& Maria, ou seja, Maria José \& Adília. De um modo geral, as leituras críticas da escrita adiliana têm salientado a ambivalência desta dualidade, que não funciona sempre do mesmo modo; eu volto a ela de tempos a tempos porque expõe uma subjectividade em processo, em mutação. Hoje, a relação entre Adília e Maria José já não é a dos primeiros livros, é outra, bastante diferente. E é sobretudo esta transformação que pretendo analisar e comentar.

\title{
2.
}

No lento processo da construção da firma Adília \& Maria José - e entenda-se o termo firma no duplo sentido de empresa e assinatura, uma firma que acima de tudo é uma forma, um estilo -, há um texto que me impressiona particularmente, sempre me impressionou. Está em O Decote da Dama de Espadas (1988), um dos mais complexos livros de Adília Lopes, e de cada vez que o leio pressinto nele algo de muito essencial:

\author{
Eu quero \\ um par de luvas \\ de que cor não sei \\ para desvestir as mãos \\ não pense que é para esconder as mãos \\ que quero desvestir as mãos \\ não tenho medo das impressões digitais \\ é para desvestir as mãos \\ é isso mesmo só isso \\ não vale a pena abrir os dedos das luvas \\ dedo a dedo \\ com a espátula de madeira
}




\begin{abstract}
não vale a pena deitar pó
de talco dentro dos dedos

essas luvas servem

para desvestir as mãos?

deixe-me ver a sua mão

I

como tem a mão

como é que fez isso?

podia responder-Ihe assim

Me gusta ver la sangre!
\end{abstract}

(2014: 121-122)

Trata-se de um texto extremamente sofrido, de resto como muitos dos primeiros poemas de Adília Lopes, e desenvolve um argumento paradoxal. Numa luvaria, alguém procura um par de luvas não para as usar, mas para pôr à vista a sua identidade mais essencial e distintiva, aquela que as impressões digitais representam e singularizam. As mãos estão em ferida, e as luvas (cujos dedos não vale sequer a pena abrir nem polvilhar com talco pois não serão calçadas) servem "para desvestir as mãos", isto é, deverão pôr a nu as mãos feridas e as respectivas impressões digitais. Muito estranhamente, ao ver as mãos magoadas, a pessoa que vende as luvas, exclama: "I / como tem a mão/ como é que fez isso?". E não sabemos se devemos ler este "I" como um "ih!" (de espanto), ou como um eu em inglês (um "I") que simultaneamente fosse um ai! interjectivo português. Com efeito, a maiúscula pode sugerir que este "I" alude ao pronome inglês de primeira pessoa misturando-o com um grito. ${ }^{2}$ A finalizar, e como justificativa do recurso a luvas que desvestem as mãos, a voz na primeira pessoa exprime um gosto masoquista por ver o próprio sangue. De notar ainda que o talco é usado apenas para abrir as luvas de pelica, o que sugere que o uso das luvas corresponde à adopção de uma segunda pele, na qual se inscrevem as mais autênticas impressões digitais.

Na obra de Adília, há várias referências a luvas e mãos enluvadas. ${ }^{3}$ No mesmo livro, um pouco antes, encontramos este poema: 


\author{
Porque tenho eu frieiras \\ se nunca tiro as luvas? \\ porque tenho eu arranhões \\ se os meus gatos são meigos? \\ como dizia uma pobre rapariga \\ que era criada e mal sabia ler \\ também eu vou dizer \\ coração partido \\ pé dormente \\ vou para a cama \\ que estou doente \\ porque me traíste tanto \\ se os meus gatos são meigos? \\ porque me atraíste tanto \\ se nunca tiro as luvas?
}

(2014: 117-118)

Já neste texto a função protectora da luva era evidenciada; e também aqui, e num registo de primeira pessoa, as mãos tinham feridas e cicatrizes, coisa que a rima entre ser atraído e ser traído parece explicar. Mas é em Sete Rios Entre Campos (1999), onze anos mais tarde, portanto, que encontramos um poema particularmente esclarecedor:

\footnotetext{
Eu sou a luva

e a mão

Adília e eu

quero coincidir

comigo mesma
}

(2014: 335)

Catorze anos depois da publicação do primeiro livro, surge na escrita de Adília Lopes um eu que exprime um desejo de resolução da dualidade Adília \& Maria José, essa "firma" que, como vimos, estava no mercado desde 1984 (e a palavra firma, recorde-se, significa antes de mais nome, assinatura, chancela, e só por extensão a firma comercial). No verso "Adília e eu", a par do desejo de coincidência, o que se enuncia é a disrupção de um eu que vê em Adília a sua alteridade. No mesmo ano, o livro Florbela Espanca Espanca, depois 
reintitulado Versos Verdes, irá incluir a seguinte advertência: "Este livro/ foi escrito/ por mim" (2014: 373). Quem subscreve esta informação? No mesmo livro, no poema "Out of the past", lemos ainda:

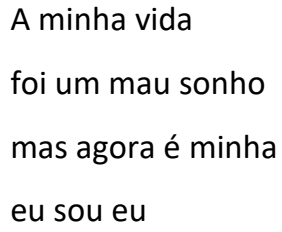

Num piscar de olhos que poucos leitores entenderão, este breve poema-anotação é dedicado a Wenceslau Passinhas, um dos dois nomes que, nos idos da década de 80, o amigo Miguel Tamen propusera a Maria José como possíveis pseudónimos. A história consta deste depoimento:

Ora, eu precisava de ter um pseudónimo e o Miguel Tamen inventou Adília Lopes e Venceslau Passinhas. Eu achei Venceslau Passinhas muito ridículo e era um nome de homem, eu não queria, portanto, ficou Adília Lopes que era de mulher. O Miguel nunca me quis dizer porque é que tinha inventado esse nome, mas uma vez eu estava a falar com um senhor no Centro de Arte Moderna que era advogado e que me disse estar convencido que Adília Lopes tinha sido uma lançadora de pesos do Sporting e também campeã olímpica ou tinha ido aos jogos olímpicos, já não sei. Realmente no José Pedro Machado em "Adília", vem uma Adília Silvério, que era atleta. (Lopes apud Evangelista 2011: 478)

Adília dedica o poema "Out of the Past" a outro possível pseudónimo porque a tautologia "eu sou eu" inverte a célebre asserção usada por Rimbaud em 1871 nas duas cartas ditas do Vidente, "eu é um outro" ("Je est un autre"). E é como se com o afastamento desta dissociação fundadora da modernidade estético-litéraria Adília reencontrasse uma subjectividade menos problemática, embora apenas pronominal, esvaziada de nomes e, logo, infixa, aberta à possibilidade. Portanto, não se trata de recuar para uma posição prémoderna, mesmo se, por extensão, parece ser afastada toda uma linhagem dissociativa da subjectividade, a começar na modernidade romântica, com a imagem do poeta-camaleão e sem nenhuma identidade, usada John Keats, e a continuar em Whitman, Dickinson, 
Mallarmé, Eliot, Pessoa. Pensemos justamente no que escreve Fernando Pessoa na carta a Casais Monteiro quando narra o dia triunfal em que escrevera "O Guardador de Rebanhos", cuja autoria é atribuída a Alberto Caeiro:

Desculpe-me o absurdo da frase: aparecera em mim o meu mestre. Foi essa a sensação imediata que tive. E tanto assim que, escritos que foram esses trinta e tantos poemas, imediatamente peguei noutro papel e escrevi, a fio também, os seis poemas que constituem a "Chuva Oblíqua", de Fernando Pessoa. Imediatamente e totalmente... Foi o regresso de Fernando Pessoa Alberto Caeiro a Fernando Pessoa ele só. Ou, melhor, foi a reacção de Fernando Pessoa contra a sua inexistência como Alberto Caeiro. (Pessoa 1999: 343)

Podemos identificar no poema de Adília uma narrativa semelhante, embora com a particularidade de não sabemos que nome apor a este "eu" reconquistado pelo "eu". O pronome descreve um regresso afim daquele que Pessoa descreve, e mais do que entre existência e inexistência, coloca-nos perante a integridade do sujeito: "eu sou eu". Mas não é possível saber quem, na firma Adília \& Maria José, fundada em 1984, diria eu nesta frase. E talvez não devamos sequer colocar esta questão, pois ela é a questão que a tautologia afasta escrupulosamente.

Um espelho
não é
uma janela
Um espelho
não é
um quadro
Quem espreita
por meus olhos
no espelho
sou eu
E eu
sou eu


Não há

enigmas

(2014: 576)

Sabemos que a obra de Adília Lopes promoveu sempre um espelhamento, em rigor um deslizamento, entre o nome civil Maria José (da Silva Viana Fidalgo de Oliveira) e inerentes vectores biográficos e familiares, por um lado, e, por outro lado, o pseudónimo que teria vindo resolver um mal-estar relativamente ao nome civil e tudo quanto ele significava de imposições identitárias. Sónia Cardoso Melo, que estudou o processo de construção da poetisa Adília Lopes, reproduz um excerto de uma entrevista dada por Adília a Carlos Vaz Marques, na qual ela esclarece:

Eu dava-me mal com o meu nome. Tinha problemas com os meus pais e o meu verdadeiro nome, o do bilhete de identidade, era o dos meus pais: Silva Viana da minha mãe, Fidalgo de Oliveira do meu pai. E Maria José por causa, dos pais, dos avós, de não sei o quê. (...) precisava de um nome escolhido por mim e queria que tudo, na capa do meu livro, fosse escolha minha. (apud Melo 2015: 78)

Nesta explicação, vemos que a criação de uma identidade autoral é claramente entendida como um processo libertário, projectivo e futurizante, em contraposição ao desconforto gerado pela identidade imposta socialmente e associada ao nome próprio. Nesse sentido, poderíamos dizer que Adília é o nome associado à busca de uma identidade projectiva emanada da subjectividade lírica. Na entrevista concedida a Carlos Vaz Marques, a autora reconhece no seu primeiro livro o teatro de uma subjectividade mais livre (da família, das imposições sociais); e é nessa medida que o nome Adília surge como a luva que permite desvestir a mão de Maria José, a mão que escrevera poemas para curar as suas feridas. 0 processo tem pontos de contacto com aquele que é narrado por Mário Cesariny no poema intitulado "A Antonin Artaud", de Pena Capital, quando recusa o nome próprio e escreve: “Haverá gente com nomes que lhes caiam bem./ Não assim eu./ De cada vez que alguém me chama Mário/ De cada vez que alguém me chama Cesariny/ De cada vez que alguém me chama de Vasconcelos/ Sucede em mim uma contracção com os dentes/ Há contra mim uma imposição violenta/ Uma cutilada atroz porque atrozmente desleal" (Cesariny 1999: 50). Ou seja: se queremos perceber o funcionamento da firma Adília \& Maria José, não 
podemos subavaliar o facto de, segundo a metanarrativa construída ao longo da obra, o nome de autor(a) Adília Lopes representar a identidade menos violentada e mais singular de Maria José: o seu devir poetisa. E para que o processo se torne legível, Adília Lopes não pode funcionar como um mero pseudónimo, ela não pode rasurar completamente o nome Maria José: sob cada um destes nomes, a obra deixa-nos ler o outro, e mostra-nos a escrita enquanto acto libertador.

Na obra de Adília Lopes, a subjectividade lírica ganha foros identitários não só porque de livro para livro se vai recuperando e consolidando a identidade social de Maria José, de quem podemos conhecer as memórias pessoais, mas também porque um pseudónimo literário é usado socialmente, e situa-se, por isso, num plano que não o da posição enunciativa do sujeito lírico de uma obra poética (mesmo se adiliana). Assim, tanto no plano intratextual quanto no plano extratextual, Adília toma o lugar de Maria José e salva-a do sofrimento: enquanto luva que expõe as feridas da mão que já não se esconde, Adília permite que os ferimentos cicatrizem; e isso só é possível porque eles também se vêem na pele de Adília, são as suas impressões digitais, são a singularidade mais profunda da mão enluvada que escreve em sofrimento nos primeiros livros.

“Diário íntimo ou fastos espiritualmente autobiográficos - a poesia é menos e é mais do que isso", afirma lapidarmente Jorge de Sena no "Prefácio da Primeira Edição" de Poesia I (1977: 27). Adília é o nome desse desfasamento e da inerente oscilação enunciativa.

3.

Quem é então, Adília Lopes? Os livros dizem-nos que é uma mulher que escreve, uma poetisa, uma filóloga e uma linguista, uma apaixonada por matemática e física, um enorme acervo de "achados/ verbais/ achados/ vitais" (2014: 497). Sabemos que é uma leitora omnívora, uma maneira de dobrar e cerzir texto com texto, poesia e vida quotidiana, um estilo. Sabemos que tem o cabelo mais encaracolado do que desejaria, que engordou muitos kilos e que agora sofre de excesso de peso e diabetes; mas também sabemos que pode desconstruir linguisticamente qualquer padrão convencional de beleza e sucesso. Adília é uma ironista, no sentido rortyano do termo, isto é, tem competências linguísticas para questionar quaisquer vocabulários e evidências, e desconfia de todas as descrições 
confrontando-as com outras descrições. E - aspecto particularmente interessante - Adília é uma subjectividade que, apesar de produzida discursivamente no âmbito da poesia, foi conquistando o estatuto de identidade autoral e pessoal. A ponto de se apropriar do mais remoto passado de Maria José e de sua família. E, o que é mais impressionante ainda, a ponto de poder substituir progressivamente o registo lírico por um registo essencialmente autobiográfico. E isto, apesar de a marca Adília ter nascido apenas em 1984, como lemos em "Poesia e Gestão".

Em 2010, Adília Lopes publica o pequeno livro Apanhar Ar, profusamente ilustrado com "Interpretações visuais através da música", uma série de riscos circulares a lápis de cor, datados de 1971, e portanto da autoria de Maria José quando tinha onze anos. Em 2013, outro pequeno volume, Andar a Pé, dá-nos diversas narrativas autobiográficas, incluindo esta:

Verdes Anos

Lembro-me com gosto do laboratório de Química do Liceu Pedro Nunes. Lembro-me da reaç̧ão do sódio com a água, liberta uma luz amarela. A reacção do potássio com água com a água liberta uma luz violeta. Tinha um colega, o Pinto, que dizia: "isto para a Maria José é melhor do que ir ao cinema". (2013: 13)

Podemos, é claro, perguntar quem diz "eu" neste texto, no qual Adília e Maria José parecem ter chegado a uma simbiose perfeita. De resto, quando, nos livros mais recentes, vemos fotografias de Maria José em criança acompanhadas de legendas que nelas identificam Adília, estamos perante um ponto radical de uma metalepse que determina toda a obra e que consiste num deslizamento entre a) o plano ontológico no qual situamos a poetisa Adília Lopes, cujo nome de autor(a) foi construído a par da "firma" (associação de assinaturas) Adília \& Maria José, b) o plano diegético em que a criança Maria José era apresentada como personagem dos livros de poemas de Adília e ainda c) o plano extradiegético no qual podemos identificar as famílias Silva Viana e Fidalgo de Oliveira, respectivamente as famílias da mãe e do pai de Maria José da Silva Viana Fidalgo de Oliveira. De resto, como recorda Sónia Cardoso e Melo (2015:73), em Os Namorados Pobres (2009) tanto Maria José como Adília são citadas enquanto nomes (e protagonistas) de textos de 
Fernando Pessoa e António Osório (Lopes 2014: 638) nos quais os seus nomes ocorrem, precisamente para nos lembrar que aqueles dois nomes designam identidades textuais.

4.

Adília Lopes é antes de mais um nome de autor(a), o pseudónimo de uma jovem poeta que começa a publicar em 1985, com vinte e cinco anos; mas quando, décadas depois, esse nome surge justaposto às fotografias de Maria José criança, ou da adolescente em que esta se tornaria nos anos 70, o nome Adília tem já uma amplitude diferente, e é-lhe atribuída uma biografia certificada no plano extradiegético com as provas de vida de... Maria José, nome que até então era aceitável entendermos como o de uma "personagem" nos poemas de Adília - tanto mais quanto essa personagem, que nos deixava suspeitas de protagonizar uma narrativa autobiográfica, se situava sempre no contexto de uma obra poética, ou seja, não sujeita a um contrato de leitura autobiográfico.

Ora, esta oscilação paradoxal constitui uma muito relevante metalepse ontológica. Como lembra John Pier, no seu sentido narratológico, a metalepse começa por ser identificada por Gérard Genette como "a deliberate transgression between the world of the telling and the world of the told" (Pier 2016:1/8), e neste caso podemos identificar diversos deslizamentos entre o plano do contar e uma diegese que pode ser ou não autobiográfica, remetendo para Adília e/ou para Maria José, ora no plano intratextual, ora no plano extratextual. Um dos traços mais originais da poesia de Adília Lopes é que desde os primeiros livros podemos identificar personagens e situações que são retomadas de livro para livro, o que faculta a construção de uma narrativa na primeira pessoa, essencialmente familiar, organizada em torno das famílias Silva Viana e Fidalgo de Oliveira. Mas, enquanto nos primeiros livros esse fio se dilui numa sucessão de ficções e citações literárias e intermediais, muitas delas reconhecíveis pelo leitor, os livros mais recentes vêm certificar essa narrativa como autobiográfica, fornecendo-nos retratos fotográficos de Maria José, e de sua mãe, do pai e de outros membros da família. E todavia, as legendas destas imagens atribuem a Adília Lopes a infância de Maria José. Eis algumas das legendas das fotografias de Manhã (2015a): “Adília, Verão de 1964”; “Adília, Cinema Europa” (na fotografia, uma criança 
fantasiada tem por detrás um cartaz com a menção Carnaval, 1969). Mais adiante, a fotografia de um bebé: “Adília com 6 meses" (2015a: 76).

Muito semelhante é o que se passa em Bandolim (2016a), que abre e fecha com duas séries de fotografias.

Na primeira, a legenda "Adília, Verão de 1964" acompanha uma nova fotografia de Maria José com quatro anos; segue-se mais uma foto de Maria José fantasiada em 1969, desta vez com a legenda "Adília, Cinema Europa". Depois, três fotografias legendadas, mas sem qualquer menção ao nome: "No colégio, uma freira ensina-me a fazer um bordado (1967-1969)"; "Rua Pascoal de Melo, Lisboa, 1975. Sou a de óculos. Fotografia tirada por um fotógrafo de rua"; "Eu em 1977 no meu quarto. A árvore atrás de mim era uma acácia". A seguir, o livro disponibiliza uma fotografia antiga: "A minha trisavó Pauline Plantier, la tigresse". A fechar esta série, uma fotografia com mãe e filha ao colo, e esta legenda: "A minha mãe e eu, 29 de Setembro de 1961".

No final do livro, outra série de fotografias de Maria José criança, cinco das quais ostentando o nome "Adília", acompanhado, em três casos, de datação. Noutras fotografias, vemos a mãe também criança, numa delas acompanhada de outras mulheres da família: a Tia Paulina, muito citada na obra, e a bisavó Maria Adelaide. ${ }^{4}$ Por fim é reproduzido um "Apontamento tirado por mim": uma página com a sugestiva transcrição manuscrita de passagens de The Great Chain of Being, de Lovejoy".

Em Estar em Casa (2018), mais fotos de família: o avô Raul em 1936, e três fotos da pequena Maria José em 1964, duas das quais com o pai. As legendas são especialmente lacónicas: "Com o meu pai, 1964" (em dois casos), e apenas "1964". Nenhuma menção, nem a Adília nem a Maria José. Como mostra Ana Bela Almeida (2016), que destaca o dístico "Na vida e no poema / dar menos um passo", de Apanhar Ar (2014: 652), a obra de Adília tem vindo a assumir um registo cada vez mais elementar e sucinto, a ponto de a própria noção de poesia poder dar lugar à simples notação diarística ou memorialística. A par dessa inflexão, os nomes Adília e Maria José foram-se tornando cada vez mais permutáveis. 


\section{Concluindo}

No uso habitual da pseudonímia, o nome de autor(a) exclui do sistema literário o nome civil. Assim, e para dar um exemplo, pseudónimos como José Régio ou Eugénio de Andrade rasuram os nomes civis José Maria dos Reis Pereira e José Fontinhas, a ponto de muitos dos leitores dos dois poetas Ihes desconhecerem totalmente os nomes de baptismo. No caso de Adília Lopes, o que comparece na obra é uma firma (Adília \& Maria José), e não chega a haver rasura do nome civil. A hibridez genológica da obra, com registos que oscilam entre a poesia e a simples notação de prosa autobiográfica, memorialística ou diarística, é o resultado formal de uma narrativa segundo a qual Adília Lopes, a salvífica luva discursiva da poesia, resgata Maria José da sua identidade civil em crise facultando-Ihe uma vida nova e livre enquanto poetisa. Ora, a obra da poetisa Adília é, antes de tudo o mais, a narrativa do processo desse salvamento (que tem duas protagonistas, não uma); por isso, a escrita organiza-se em função da poesia (lirismo) e do contar da emergência da poesia na vida como acontecimento ou acto (autobiografia), tornando-se genologicamente híbrida.

Esse hibridismo é um modo radical de metalepse pois funde e confunde sistematicamente lirismo e autobiografia, enquanto na tradição moderna o lirismo tinha sido entendido como uma forma extrema de fuga à autobiografia. É por este motivo que o nome Adília Lopes de modo algum pode ser um mero pseudónimo: ele protagoniza um processo de devir outro através da escrita no plano identitário e não no plano da impessoalidade, ou destruição da identidade. Em rigor, quando o salvamento se completa, a equação "eu sou eu" significa que os dois nomes (literário e civil) podem ser permutáveis (e já não apenas justapostos): Maria José pode ser Adília em qualquer circunstância intra ou extratextual e, portanto, "não há enigmas" - há actos poéticos, há a poesia em acto. Em Le Vitrail la Nuit A Árvore Cortada (2006), podemos ler:

Acho
que não preciso
de escrever
mais
Acho
que já não


quero escrever

Acho

que estou

a deixar

de escrever

(2014: 598)

E talvez o melhor epílogo para tal aventura esteja neste texto de Café e Caracol, que propõe um outro sentido para a escrita: "Não escrevo para me dizer. Escrevo para fazer inscrições, desenhos" (2014: 662). Estava, pois, consumado o salvamento.

\section{NOTAS}

${ }^{1} \mathrm{O}$ título da célebre canção do álbum Sgt. Pepper's Lonely Hearts Club Band é reproduzido mais tarde, com uma ligeira alteração, em Capilé, no poema "Nave de Haver", no qual "Os meus/ dois seios/ nas tuas/ duas mãos" são descritos como "lúcias no céu/ com diamantes" (2016b: 27).

${ }^{2}$ Seria de recordar, a este propósito, o seguinte poema de Le Vitrail la Nuit - A Árvore Cortada, dedicado a Rimbaud e concebido em diálogo intertextual com o soneto "Voyelles": O I é encarnado/ é vermelho/ ruge/ como o leão/ range/ como a madeira/ grita/ como a mulher/ a parir// Ir/ ira// Iraque (2014: 579).

${ }^{3}$ Também de O Decote da Dama de Espadas, cf. "A luva branca" (2014: 127), e de Maria Cristina Martins, "[Um mendigo saiu de um portal]" (id.: 183).

${ }^{4}$ Recorde-se, por exemplo, os poemas "Tia Paulina", de Manhã (2015a: 75), e "História da Língua Portuguesa", de Comprimidos, no qual a Tia Paulina é protagonista (2015: 12). Veja-se ainda "No quarto da tia Paulina", de $O$ Peixe na Água (2012: 192), e a citação da Tia Paulina em Estar em Casa (2018: 31). 


\section{Bibliografia}

Almeida, Ana Bela (2016), Adília Lopes, Coimbra, Imprensa da Universidade de Coimbra.

Cesariny, Mário (1999), Pena Capital, 2ª ed., Lisboa, Assírio \& Alvim.

Evangelista, Lúcia Liberato (2011), Pôr a vida em comum: a poética de Adília Lopes, dissertação de Mestrado apresentada à FLUP. https://repositorioaberto.up.pt/ bitstream/10216/57408/2/TESEMESLUCIAEVANGELISTA000148379.pdf (Consultado em 16 de Abril de 2019).

Melo, Sónia Rita Cardoso (2015), Des-Dobra: re-visão e tradução - A construção da poetisa em Adília Lopes, Tese doctoral, Barcelona, Universitat de Barcelona. http://diposit.ub.edu/dspace/bitstream/2445/66446/1/SRCM_TESE.pdf (Consultado em 16 Abril de 2019).

Lopes, Adília (2010), Apanhar Ar, Lisboa, Assírio \& Alvim.

-- (2013), Andar a Pé, Lisboa, Edições Averno.

-- (2014), Dobra - Poesia Reunida, 2a ed., Porto, Assírio \& Alvim /Porto Editora [1a ed. 2009].

-- (2015), Comprimidos, encarte da revista Telhados de Vidro, № 20.

-- (2015a), Manhã, Porto, Assírio \& Alvim/ Porto Editora.

-- (2016), Z/S, Lisboa, Averno.

-- (2016a) Bandolim, Porto, Assírio \& Alvim/ Porto Editora.

-- (2016b), Capilé, Lisboa, Averno.

Pessoa, Fernando (1999), Correspondência 1923-1935, ed. Manuela Parreira da Silva, Lisboa, Assírio \& Alvim.

Perloff, Marjorie (2013), O Gênio Não Original - Poesia por outros meios no novo século, Belo Horizonte, Editora UFMG.

Pier, John (2016), "Metalepsis" (revised version; uploaded 13 July 2016)”, in Hühn, Peter et al (eds.), The Living Handbook of Narratology, Hamburgo, Uni. De Hamburgo, URL= 
http://www.Ihn.uni-hamburg.de/article/metalepsis-revised-version-uploaded-13-july-2016 (consultado a 12 de Fevereiro de 2019).

Sena, Jorge de (1977), “Prefácio da Primeira Edição” (1961), Poesia I, 2aed., Lisboa, Moraes.

Rosa Maria Martelo é ensaísta e professora de Literatura e Estudos Interartísticos na Faculdade de Letras da Universidade do Porto, Portugal. Tem privilegiado o estudo da poesia portuguesa e das poéticas modernas e contemporâneas. Como investigadora do Instituto de Literatura Comparada Margarida Losa (I\&D FCT), interessam-lhe as relações de intermedialidade, particularmente os diálogos da poesia com as artes visuais e audiovisuais. Publicou os seguintes livros de poesia: A Porta de Duchamp (2009), Matéria (2014) e Siringe (2017). Entre os livros de ensaios mais recentes contam-se A Forma Informe - Leituras de Poesia (2010), O Cinema da Poesia (2012, 2a ed. 2017) e Os Nomes da Obra - Herberto Helder ou o Poema Contínuo (2016). Co-organizou a antologias Poemas com Cinema (2010) e Uma Espécie de Cinema (2019) e o volume Ofício Múltiplo - Poetas em Outras Artes (2017). 